\title{
BMJ Open Quantifying within-city inequalities in child mortality across neighbourhoods in Accra, Ghana: a Bayesian spatial analysis
}

Honor Bixby (D) , ${ }^{1,2}$ James E Bennett, ${ }^{3,4}$ Ayaga A Bawah, ${ }^{5}$ Raphael E Arku, ${ }^{6}$ Samuel K Annim, ${ }^{7,8}$ Jacqueline D Anum, ${ }^{7}$ Samilia E Mintah, ${ }^{7}$ Alexandra M Schmidt, ${ }^{1}$ Charles Agyei-Asabere, ${ }^{5}$ Brian E Robinson, ${ }^{9}$ Alicia Cavanaugh, ${ }^{9}$ Samuel Agyei-Mensah, ${ }^{10}$ George Owusu, ${ }^{11}$ Majid Ezzati, ${ }^{3,4,5,12}$ Jill Baumgartner ${ }^{1,2}$
To cite: Bixby H, Bennett JE, Bawah AA, et al. Quantifying within-city inequalities in child mortality across neighbourhoods in Accra, Ghana: a Bayesian spatial analysis. BMJ Open 2022;12:e054030. doi:10.1136/ bmjopen-2021-054030

- Prepublication history and additional supplemental material for this paper are available online. To view these files, please visit the journal online (http://dx.doi.org/10.1136/ bmjopen-2021-054030)

Received 01 June 2021 Accepted 18 December 2021

Check for updates

(C) Author(s) (or their employer(s)) 2022. Re-use permitted under CC BY. Published by BMJ.

For numbered affiliations see end of article.

Correspondence to

Dr Honor Bixby;

honor.bixby@mcgill.ca

\section{ABSTRACT}

Objective Countries in sub-Saharan Africa suffer the highest rates of child mortality worldwide. Urban areas tend to have lower mortality than rural areas, but these comparisons likely mask large within-city inequalities. We aimed to estimate rates of under-five mortality (U5M) at the neighbourhood level for Ghana's Greater Accra Metropolitan Area (GAMA) and measure the extent of intraurban inequalities.

Methods We accessed data on $>700000$ women aged 25-49 years living in GAMA using the most recent Ghana census (2010). We summarised counts of child births and deaths by five-year age group of women and neighbourhood $(n=406)$ and applied indirect demographic methods to convert the summaries to yearly probabilities of death before age five years. We fitted a Bayesian spatiotemporal model to the neighbourhood U5M probabilities to obtain estimates for the year 2010 and examined their correlations with indicators of neighbourhood living and socioeconomic conditions.

Results U5M varied almost five-fold across neighbourhoods in GAMA in 2010, ranging from 28 (95\% credible interval (Crl) 8 to 63$)$ to $138(95 \% \mathrm{Crl}$ 111 to 167) deaths per 1000 live births. U5M was highest in neighbourhoods of the central urban core and industrial areas, with an average of 95 deaths per 1000 live births across these neighbourhoods. Peri-urban neighbourhoods performed better, on average, but rates varied more across neighbourhoods compared with neighbourhoods in the central urban areas. U5M was negatively correlated with multiple indicators of improved living and socioeconomic conditions among periurban neighbourhoods. Among urban neighbourhoods, correlations with these factors were weaker or, in some cases, reversed, including with median household consumption and women's schooling.

Conclusion Reducing child mortality in high-burden urban neighbourhoods in GAMA, where a substantial portion of the urban population resides, should be prioritised as part of continued efforts to meet the Sustainable Development Goal national target of less than 25 deaths per 1000 live births.

\section{Strengths and limitations of this study}

- We accessed the full microdata of the latest census (2010) in Ghana that contained birth history data for over 700000 women aged 25-49 years living in the Greater Accra Metropolitan Area.

- Georeferenced census data allowed for estimation of under-five mortality at the fine spatial scale of neighbourhood, with full coverage of the Greater Accra Metropolitan Area.

- We used a flexible Bayesian spatiotemporal model that allowed each neighbourhood's mortality estimate to be informed by its own data and that of surrounding neighbourhoods, and incorporated weights for the number of births recorded.

- Under-five mortality was indirectly calculated from the summary birth history data because complete birth and death registration data were unavailable. These data may be subjected to recall errors. No data were available on the cause of death.

\section{BACKGROUND}

Recent decades have delivered marked reductions in child mortality across all world regions. ${ }^{1}$ Despite improvements, almost $8 \%$ of all deaths globally in 2019 were children under five years of age, ${ }^{2}$ mostly due to preventable and treatable causes linked to infection and malnutrition. ${ }^{3}$ The rate of under-five mortality (U5M) in sub-Saharan Africa (SSA) far exceeds other regions, estimated at 76 deaths per 1000 live births in 2019, and under-five deaths in the region account for a growing proportion of the global total. ${ }^{1}$

On average, children living in cities across low-income and middle-income regions have a survival advantage over their rural counterparts, largely due to improved education, employment and healthcare opportunities in urban areas. ${ }^{4-6}$ While still predominantly 
rural, SSA has the world's fastest-growing urban population and cities are expected to absorb over $75 \%$ of the region's population growth over the next three decades. ${ }^{7}$ This offers many opportunities for continued improvement in child mortality, however, infrastructure and basic service provision remain major challenges for cities in the region, exacerbated by the rapid pace of urban population growth. Over half of the urban population-more than in any other world region-lives in slums and informal settlements that are often characterised by poverty and concentrated deprivation. ${ }^{8}$

The social determinants of health refer to the conditions in which people are born, grow, live, work and age and have important influence on health inequalities. ${ }^{910}$ Social gradients in the health of children are well documented, whereby children born into deprivation have lower chances of survival and prosperity. ${ }^{9-11}$ In cities, health outcomes and their social, economic and environmental determinants can vary dramatically between households and neighbourhoods. ${ }^{12} 13$ The mortality gap between children living in slum versus non-slum urban areas in SSA, for example, can be as large as the gap between rural and urban children. ${ }^{6}{ }^{14-16}$ Inadequate housing, electricity and clean fuel access, water and sanitation facilities, nutrition and healthcare services are among the pathways through which low income or education levels, among other factors termed 'social stratifiers', ${ }^{9}$ can increase the susceptibility or hazardous exposures of those most deprived. These mechanisms can act at the individual and household level or at the area level, whereby people with the fewest means are spatially sorted into neighbourhoods with the poorest infrastructure, known as segregation. ${ }^{1718}$ This in turn can contribute to intraurban health inequalities, including in child mortality, seen at the small area level, where advantage tends to cluster. ${ }^{13161920}$

There is substantial evidence that health outcomes vary at small spatial scales ${ }^{21-26}$ and local neighbourhood factors are increasingly recognised as important drivers of population health inequalities. ${ }^{21}{ }^{27-30}$ Subnational estimates of child mortality are often at too course of a scale to capture local variation across cities. ${ }^{22} 3132$ Increased knowledge of the spatial heterogeneity of child mortality within cities at finer scales in SSA countries is necessary to target interventions and programmes towards highrisk populations, accelerate progresstoward the United Nations Sustainable Development Goal (UN SDG) target of less than 25 deaths per 1000 live births for all countries by 2030 (Goal 3, Target 3.2) ${ }^{33}$ and better understand the determinants of such inequalities. ${ }^{34}$

With unique access to the complete records of the most recent Ghana Population and Housing Census, ${ }^{35}$ we aimed to estimate rates of U5M at the neighbourhood level across the Greater Accra Metropolitan Area (GAMA), providing insight into the magnitude of intraurban inequalities in child mortality within a rapidly growing, low-middle-income city. We quantified U5M rates for 2010, the year of the census, and, aligned with previous studies using census data, examined their relationships with neighbourhood-level indicators of socioeconomic and living conditions. ${ }^{21} 2628$ This study was conducted within the Pathways to Equitable Healthy Cities study (http://equitablehealthycities.org/).

\section{METHODS}

\section{Study setting}

Ghana is among the most urbanised countries in SSA with an estimated urban population of over 18 million in 2021 (58\% of the total population), that is growing by $\sim 3 \%$ each year. ${ }^{7}$ GAMA is Ghana's administrative and economic capital and accounted for $29 \%$ of the country's urban population in $2010 .^{35}$ It covers $\sim 1500 \mathrm{~km}^{2}$ on the southern coast of the Greater Accra region. According to the 2010 census, GAMA comprises 5019 enumeration areas (EAs) - the smallest administrative geographical unit in Ghana-nested within 406 localities and 12 districts or 'municipalities' (figure 1).

The centrally located Accra Metropolitan Area (AMA) - together with the more heavily industrialised Tema and Ashaiman municipalities to the southeastcontain the most densely populated neighbourhoods. AMA contains the central business district and functions as the city's commercial, industrial and administrative centre. $^{36}{ }^{37}$ Rapid development since Ghana's independence in 1957 has contributed to increased congestion in AMA's residential areas. Planned residential neighbourhoods in AMA remain as legacies of the colonial era, while migrants and low-income individuals have been pushed into slums and other low-income neighbourhoods that can lack basic services and infrastructure. ${ }^{17}$ Tema is GAMA's planned industrial hub with structured housing developments and services, and was the fastestgrowing municipality following independence. A small fraction $(\sim 5 \%)$ of GAMA's population lives in areas classified in the 2010 census as rural, mostly in northern GAMA and predominantly in the Ga West and Ga South districts. These districts are characterised by sprawling urban development with high rates of population growth since the 1970s due to congestion of the city centre. ${ }^{3638}$

Overall, the U5M rate in Ghana almost halved from 1990 to 2010, though considerable subnational inequality persisted. ${ }^{131} 32$ During this period, the government implemented several national health policies and programmes to improve the use and delivery of maternal and child healthcare services. ${ }^{39}$ The National Health Insurance Scheme (NHIS) provides free healthcare to participants ${ }^{40}$ and, in 2008, enrolment was made free of charge for pregnant women and children under 18 years of age. ${ }^{41}$ Antenatal and postnatal visits, facility delivery (including emergency obstetric care) and neonatal care are all included under the scheme. The User Fees Exemption for Delivery Care was scaled up in 2005 and exempts pregnant women who are not enrolled in NHIS from paying delivery fees. ${ }^{42}$ Ghana's 2007-2015 Child Health Policy aimed to unify fragmented programme delivery under a recommended continuum of care for mothers 


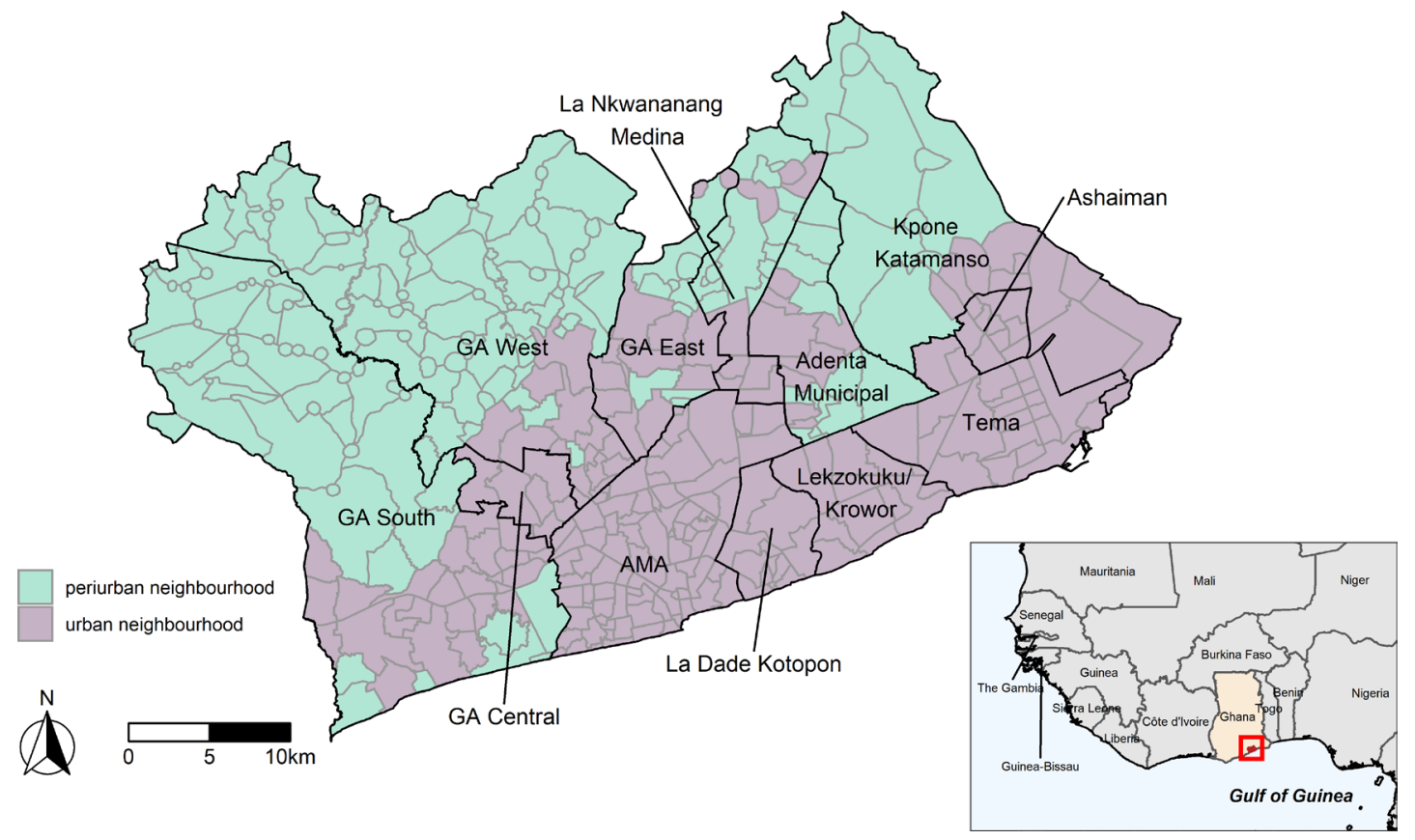

Figure 1 The Greater Accra Metropolitan Area (GAMA) with neighbourhood boundaries shown in grey and district boundaries shown in black (grey) (source: Ghana Statistical Service). Urban neighbourhoods are shown in purple and peri-urban neighbourhoods shown in green. The inset shows the location of GAMA in Ghana and Western Africa.

and children, scaling up interventions with proven efficacy to prevent child deaths, including, for example, oral rehydration therapy and zinc for treatment of diarrhoea, vitamin A supplementation and antibiotic treatment for pneumonia. ${ }^{43}$ Together, these efforts have contributed to reductions in overall child mortality and in inequalities between subregions, though wider concerns have persisted over the quality of care. ${ }^{44}$ In Accra, women enrolled in NHIS were found more likely to seek formal care and visit clinics, but enrolment rates were lower (under 35\%) among women of childbearing age compared with women over the age of $50 .{ }^{41}$ Although most births $(>90 \%)$ in Greater Accra take place in a health facility in the presence of a skilled health professional, the coverage rate of age-appropriate vaccines in children drops with age (from $76 \%$ to $48 \%$ comparing children aged 1 vs children aged 2-3 years, respectively). This indicates considerable variability in continued access to care for children. ${ }^{45}$

\section{Data}

We accessed the full microdata of the most recent Ghana Population and Housing Census, conducted in 2010, via the Ghana Statistical Service. The census collected information on the number of children born and surviving at the time of survey, known as their summary birth history, for all women aged 12 years and older. Other individual and household characteristics captured in the census include employment status, occupational industry, schooling level, literacy, household amenities (including type of cooking fuel, drinking and non-drinking water source, sanitation facilities, lighting source and waste disposal method in use), dwelling type and structural features (including roof, floor and wall materials) and EA of residence. Together, these provide information on the socioeconomic and living environments.

We obtained a shapefile from the Ghana Statistical Service with all GAMA EAs, localities and districts geocoded according to the 2010 census geographies. Localities within GAMA were the neighbourhood units used in our analysis, each containing between 1 and 95 EAs. We linked the census data and the shapefile using codes that uniquely identified EAs to determine each individual's neighbourhood of residence. Neighbourhoods were defined by the Ghana Statistical Service and are the administrative units at which urban versus rural classification is defined in Ghana; those with 5000 inhabitant or more are considered urban, and rural otherwise. Some neighbourhoods were recently subdivided due to population growth and, thus, did not meet the urban population threshold despite the urban designation of their constituent EAs in the census. We, therefore, classified GAMA neighbourhoods as urban or periurban according to the historic census-derived urban-rural designation of their constituent EAs. Most neighbourhoods (98\%) comprised exclusively urban or exclusively rural EAs. We classified neighbourhoods that contained both urban and rural EAs as urban if over $50 \%$ of the population lived in urban EAs and periurban otherwise (figure 1). Ghana does not have an official definition that distinguishes periurban from rural neighbourhoods; however, we used the term periurban to better describe 'rural' neighbourhoods that are located within the administrative border of GAMA on the periphery of the densely populated inner-city and industrial areas (figure 1). 
To assess U5M, we summarised the birth history data of women of reproductive age (15-49 years) by five-year age group and neighbourhood. The Maternal Age Cohort (MAC) method was used to estimate the neighbourhood probability of death for children before the age of five (5q0) for each five-year age group, based on the number of children ever born, proportion of children who have died and average parity. ${ }^{46}$ The MAC method outperforms alternative methods for estimating U5M from summary birth history data for subnational populations. ${ }^{47}$ Each $5 \mathrm{q} 0$ was assigned to a reference year prior to the census, using maternal age as a proxy measure for duration of exposure to risk of death for a child. The assigned $5 \mathrm{q} 0$ reference years covered the period from 1990 to 2005 . We excluded $5 \mathrm{q} 0$ estimates derived from women aged 15-19 and 20-24 years, owing to the low numbers of births recorded for these age groups in many neighbourhoods, which could lead to spurious fluctuations in the $5 \mathrm{q} 0$ estimates, especially in the more sparsely populated periurban areas. Notably, this is common practice when using demographic methods to estimate population U5M rates. ${ }^{46-48}$ This left five $5 q 0$ estimates for each neighbourhood (one derived from each five-year age group of women aged 25-49 years).

\section{Statistical analysis}

To obtain neighbourhood estimates of $5 \mathrm{q} 0$ for 2010 , the year of the census, we fitted a Bayesian spatiotemporal model to the MAC-derived $5 \mathrm{q} 0$ estimates across all 2030 neighbourhood-reference year units, transformed to the probit scale. The model included a linear time trend that could vary by neighbourhood. The time trend allowed data from different reference years, each of which is associated with a different age group, to inform the $5 \mathrm{q} 0$ in 2010 . The neighbourhood intercepts and slopes were modelled using the Besag, York and Mollié model, ${ }^{49}$ where information is shared locally (ie, among adjacent neighbourhoods) through spatially structured random effects with a conditional autoregressive prior and globally through spatially unstructured Gaussian random effects. Neighbourhood-specific intercept and slope values were estimated by the sum of their respective spatially structured and spatially unstructured random effects. The prior distributions in the Bayesian framework allow the neighbourhood-specific parameters to be estimated by a neighbourhood's own data and data of contiguous neighbourhoods. This approach balances overly unstable within-neighbourhood estimates and overly simplified aggregate estimates for all of GAMA. The reported estimate for the wealthy Ringway neighbourhood in AMA is informed entirely by data in bordering neighbourhoods as the data on child deaths were considered implausible (see online supplemental appendix 1). To account for excess variability resulting from small numbers of children born to women in a given age group and neighbourhood, we included a weighted variance term that gave more weight to estimates derived from a higher number of births. Samples from the posterior distributions of the intercepts and slopes were used to estimate $5 \mathrm{q} 0$ for the year 2010 .

To avoid infinite values on the probit scale, we adjusted all MAC-derived $5 \mathrm{q} 0$ estimates of zero $(\mathrm{n}=146 ; 7 \%)$ to half the minimum estimated non-zero value across all units $(0.00316)$. We conducted sensitivity analyses to ensure that our results were robust to this choice by replacing zero estimates with a lower value of 0.0001 and with the minimum estimated nonzero $5 \mathrm{q} 0$.

We monitored convergence using trace plots and obtained 5000 post burn-in samples from the posterior distributions of model parameters. We summarised the distributions of neighbourhood-specific parameters to report neighbourhood $\mathrm{U} 5 \mathrm{M}$ estimates and mean U5M across neighbourhoods within districts for 2010, with $95 \%$ credible intervals (CrI) that represent the mean and the 2.5th and 97.5th percentiles of the posterior samples, respectively. We present neighbourhood U5M estimates as deaths per 1000 live births.

We calculated neighbourhood-level summary statistics of individual and household characteristics to provide context for our mortality results. We used the withinneighbourhood median household consumption as a measure of neighbourhood socioeconomic level. Household consumption is considered a better indicator of living standards than household income in low-income and middle-income settings. ${ }^{50} 51$ The census did not include consumption data, so we used small-area estimation methods to indirectly calculate consumption based on household characteristics described in detail elsewhere. ${ }^{52}$ Briefly, we used the 2012 Ghana Living Standards Survey to develop a statistical relationship between household characteristics and consumption. Then using those same household characteristics, we predicted consumption for households in the census. We additionally calculated population density; the proportion of the women of reproductive age (15-49 years) who were literate, had schooling to at least primary, middle, secondary and postsecondary levels; the proportion of the working age (15-64 years) population in any employment and in primary, secondary and tertiary sector occupations; and the proportion of households with indicators of improved living conditions (including dwelling type, materials of flooring, roofing and walls, methods of solid and liquid disposal, type of toilet facility, type of cooking fuel and type of drinking and other water source). Details of our classification of the census responses into indicators of 'improved' versus 'unimproved' living conditions are provided in online supplemental appendix 2.

We measured the correlations between neighbourhood U5M and neighbourhood socioeconomic and living environment indicators using the non-parametric Spearman's rank method. We measured the correlations across all GAMA neighbourhoods and separately across urban and periurban neighbourhoods. 

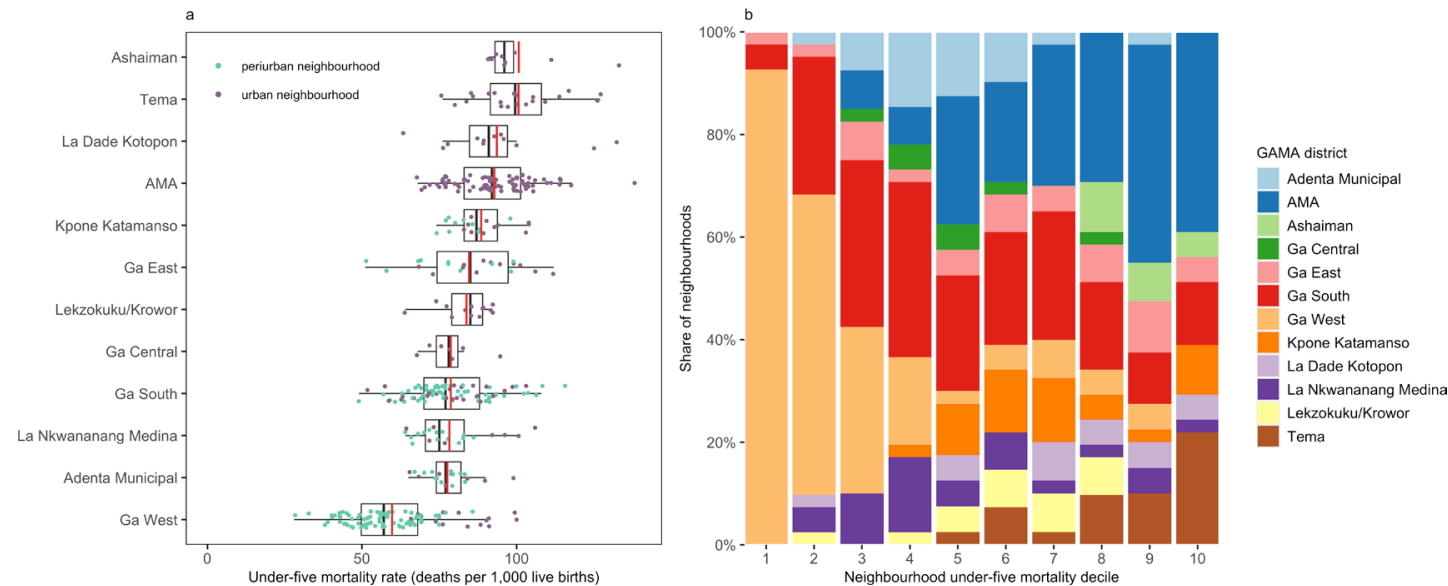

Figure 2 (A) Neighbourhood under-five mortality in the Greater Accra Metropolitan Area (GAMA) in 2010, by district. The black vertical line and box show the median and IQR of under-five mortality across neighbourhoods in a district and the red vertical line shows the mean. (B) The contribution of neighbourhoods in each district to each decile of neighbourhood under-five mortality. Decile 1 groups the $10 \%$ of neighbourhoods with the lowest under-five mortality rates and decile 10 groups the $10 \%$ of neighbourhoods with the highest under-five mortality rates.

All analyses were implemented in the open-source statistical software R V.3.6.1. The Bayesian model was implemented using the NIMBLE package V.0.9.1.

\section{Patient and public involvement}

The study used secondary data only.

\section{RESULTS}

There were 713581 women aged 25-49 years living in GAMA in 2010, who reported a total of 1425008 children, $1312030(92.1 \%)$ of whom were alive at the time of the census. The number of women in this age range per neighbourhood ranged from 15 to 16061 (median=564). The proportion of their children born who had died ranged from $0 \%$ to $20 \%$ across neighbourhoods.

In 2010, the mean neighbourhood U5M rate in GAMA was 80 deaths per 1000 live births (95\% CrI 76 to 84). This compares to an estimated 69 deaths per 1000 live births nationally in Ghana. ${ }^{1}$ Across all of GAMA, neighbourhood U5M varied almost five-fold, ranging from 28 deaths per 1000 live births (95\% CrI 8 to 63) in the Fantsenkor neighbourhood located in the north of GAMA to 138 deaths per 1000 live births (95\% CrI 111 to 167 ) in the Mamobi neighbourhood in the city's urban core (figures 2A and 3). The variation was higher across periurban neighbourhoods compared with across urban neighbourhoods, ranging from 28 to 116 versus from 52 to 138 deaths per 1000 live births, respectively.

We found substantial variation in U5M between and within GAMA's 12 districts. The within-district mean neighbourhood U5M was highest at 101 deaths per 1000 live births in the Tema (95\% CrI 89 to 113) and Ashaiman (95\% CrI 89 to 114) municipalities situated in the southeast and east of GAMA, respectively. Both municipalities comprised only urban neighbourhoods. The withindistrict mean neighbourhood U5M was lowest in the
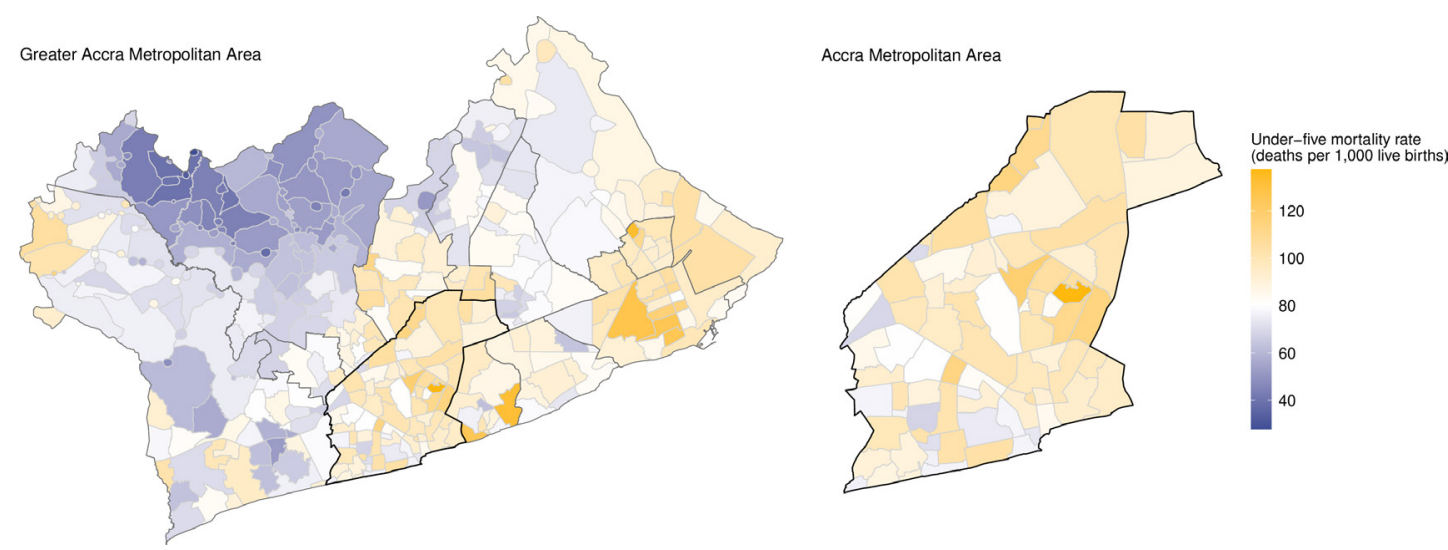

Figure 3 Under-five mortality rates in neighbourhoods of the Greater Accra Metropolitan Area (GAMA) in 2010. Neighbourhood boundaries are shown in grey, and district boundaries are shown in black. The Accra Metropolitan Area (AMA) bourndary is emphasised. The colour scale diverges at the mean under-five mortality rate across all GAMA neighbourhoods. Neighbourhoods with U5M above the GAMA average are shown in orange; neighbourhoods with U5M below the GAMA average are shown in purple. 
northern Ga West district (60 deaths per 1000 live births, $95 \%$ CrI 52 to 68 ), where over $70 \%$ of neighbourhoods were considered periurban (figure 2A). Although Ga West had the lowest mean mortality among GAMA districts, it had the highest within-district inequality (measured as the relative difference between the neighbourhood with the highest vs lowest mortality), with a 3.6-fold difference between the worst- and best-performing neighbourhoods. Within-district inequality was lowest in the Ga Central and Kpone Katamanso municipalities (1.4-fold difference across neighbourhoods).

The $10 \%$ of neighbourhoods with the lowest U5M were concentrated in just three neighbouring districts in western GAMA, namely, Ga West, Ga East and Ga South. The $10 \%$ of neighbourhoods with the highest U5M were more dispersed, present in eight of the 12 GAMA districts, though over a third of the highest mortality neighbourhoods fell within the urban core of AMA (figure 2B). Neighbourhood mortality was consistently high in AMA, where $80 \%$ of neighbourhoods $(n=64)$ had U5M rates higher than the mean across GAMA neighbourhoods. This was true also for the Tema and Ashaiman municipalities, where $95 \%$ and $100 \%$ of neighbourhoods, respectively, had higher than average U5M (figure 3). The spatial pattern of U5M reported was unchanged in our sensitivity analyses (online supplemental appendix 3). The mean absolute difference in neighbourhood U5M estimates was 2.24 deaths per 1000 live births in our analysis replacing zero estimates of $5 \mathrm{q} 0$ with 0.0001 and -0.73 in our analysis replacing zero estimates with the minimum estimated non-zero $5 \mathrm{q} 0$ value.

The correlations between neighbourhood U5M and indicators of improved living and socioeconomic conditions in periurban areas were distinct from urban neighbourhoods located mostly in the urban core and industrial areas (table 1). In periurban areas, U5M was inversely correlated with most of the indicators of improved neighbourhood conditions analysed. The strongest associations were with the proportions of neighbourhood residents living in houses built with improved wall and roof materials, and with an improved lighting source, followed by the share of women aged 15-49 with at least primary or middle school education or who were literate (Spearman's $\rho$ : -0.41 to -0.50 ). By comparison, correlations were weaker or reversed in urban neighbourhoods. Similar inverse correlations, though smaller in magnitude (Spearman's $\rho$ : -0.14 to -0.23 ), were found with the share of working age population engaged in secondary or tertiary sector occupations and the proportion of residents living in housing with improved wall and roof materials. No relationship was found for several indicators, including levels of women's literacy and access to improved drinking water source (Spearman's $\rho: 0.12$ and -0.02 , respectively). For others, there was a positive correlation, most notably with indicators of socioeconomic status, for example, the share of women educated to middle school level or above and average household consumption (Spearman's $\rho: 0.14$ to 0.35 ).

\section{DISCUSSION}

Our high spatial resolution analysis of child mortality in GAMA, one of the largest metropolitan areas in SSA, revealed considerable intraurban inequality in U5M, with the highest levels in neighbourhoods located in the city's urban core and more heavily industrial areas. Notably, even GAMA's lowest mortality neighbourhood had a mortality rate equivalent to the Dominican Republic and Bhutan, which ranked 129th and 130th, respectively, among countries and territories worldwide in the UN's most recent estimates. ${ }^{1}$ At present, no country has an estimated average child mortality rate as high as GAMA's highest mortality neighbourhood.

A general pattern of higher child mortality extended across inner-city and more industrial neighbourhoods, despite higher median household consumption and generally higher levels of post-primary education among women in these neighbourhoods relative to their periurban counterparts. Moreover, child mortality tended to be higher in better-off neighbourhoods of urban GAMA. The spatial concentration of people across a wide socioeconomic spectrum may generate what has been termed 'negative health externalities', 13 whereby localised inequalities compromise the real or perceived capacity of low-resourced individuals to sustain good health. Households that are better off may be negatively impacted by environmental degradation that is not bounded by household or neighbourhood boundaries, for example, poor community sanitation or air pollution from neighbours' solid waste burning or household use of solid fuel stoves. ${ }^{53-55}$ It is important to highlight, however, that we cannot draw firm conclusions regarding the harmful impact of localised socioeconomic inequalities on the health of individuals within neighbourhoods from these observed correlations in our study. Associations at the area level that include neighbourhoods with diverse populations may simply obscure any association between wealth and health operating at the individual or household level.

Child mortality can be seen in some places to follow historical patterns of socioeconomic segregation in central Accra. ${ }^{17}$ The wealthier Cantonments neighbourhood-home to European settlers in the colonial erawas among the pockets of lower-than-average U5M (63 deaths per 1000 live births), contrasted with higher rates found in low-income or 'slum' neighbourhoods, including Mamobi, Nima and New Town (83-138 deaths per 1000 live births). However, other low-income neighbourhoods had U5M rates below the GAMA average, for example, Jamestown and Sabon Zongo. The health penalty of areas with concentrated poor living conditions that arise from rapid, unplanned population growth, compiled by underinvestment in public services and infrastructure, in SSA cities is well established and supported by previous studies conducted in central Accra and Nairobi. 6 14 56-59 The high mortality rates in city slums in Kenya is thought to have contributed to stalled progress in urban compared with rural areas. ${ }^{59}$ The variation seen across poor areas suggests distinct characteristics of these neighbourhoods 


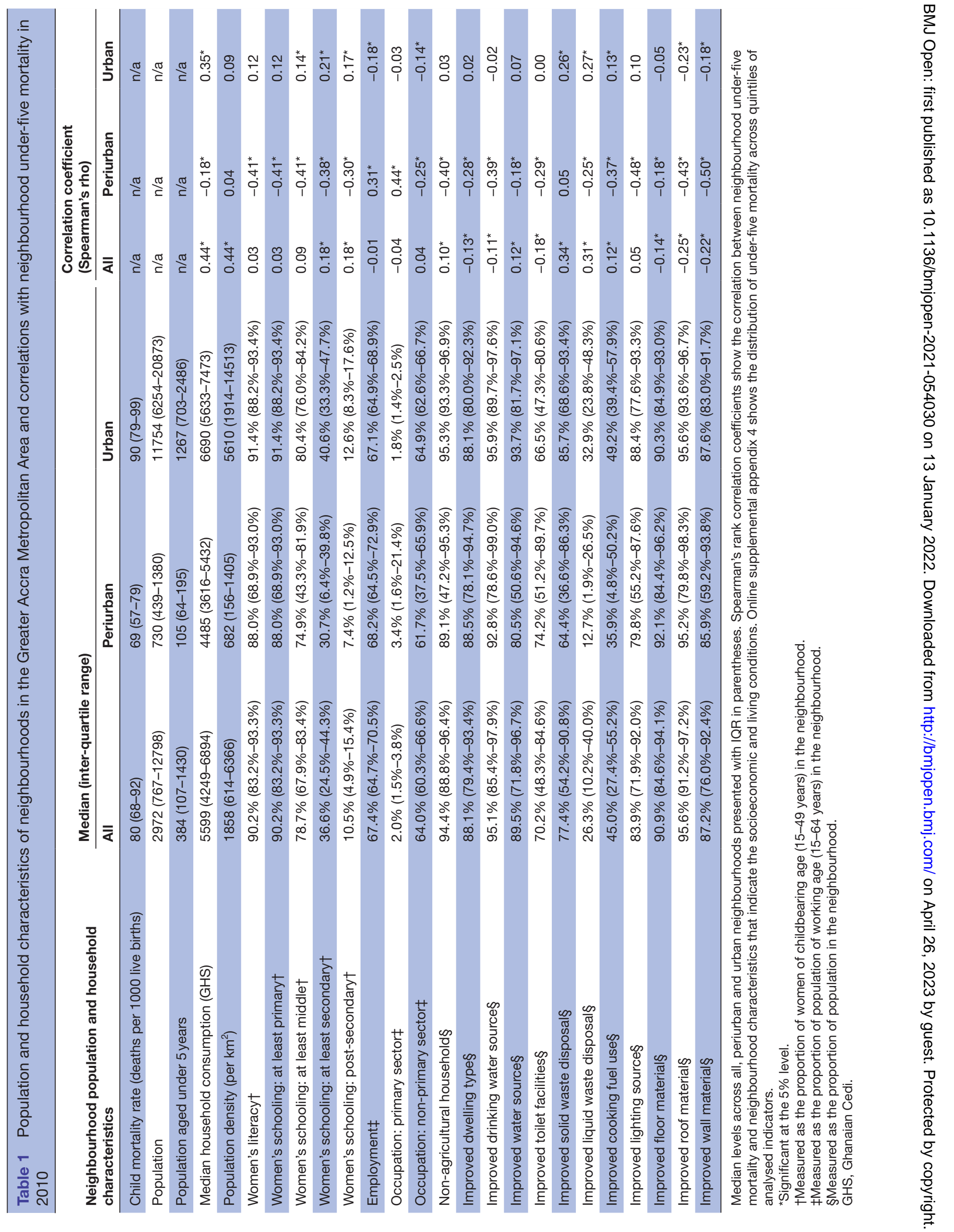


and vulnerabilities of the people living in them. ${ }^{53} 60-63$ Lower U5M rates in some of these neighbourhoods may reflect the success of targeted interventions to reduce mortality in the poorest communities. ${ }^{64}$

We observed the lowest rates of U5M in periurban neighbourhoods, where residents can still benefit from the urban services that contribute to improved child survival in cities, but avoid the potential hazards of innercity living. A healthy selection effect may also contribute to the observed pattern of U5M, where recent development of periurban neighbourhoods has encouraged wealthier residents to move out of the inner city in search of better standards of living. Some of the areas considered periurban in the Ga districts are more recently developed neighbourhoods mostly occupied by middle-income and high-income individuals. Our finding of lower U5M in neighbourhoods with improved socioeconomic and living conditions in the periurban area is consistent with the established social gradient in child mortality ${ }^{9-11}$ and with evidence linking the neighbourhood environment to population health inequalities. ${ }^{21}{ }^{27-30}$ It may reflect greater access to services including healthcare for women in these neighbourhoods, which can influence the health of mothers and their children. However, these reported ecological correlations only provide broader context to the observed spatial patterns of U5M across GAMA and should not be interpreted as causal.

A notable strength of our study is the fine spatial resolution of our U5M estimates, enabled by access to the full microdata of the 2010 census, including birth histories of over 700000 women. Previous knowledge of child mortality inequalities in the metropolitan area was limited to broad district aggregates ${ }^{3132}$ or smaller areas in the urban core ${ }^{61}{ }^{65}$ thereby excluding almost half of GAMA's total population, including residents of the rapidly developing Ga districts and the industrial Tema area. ${ }^{66}$ In the absence of complete birth and death registration, summary birth history data used in our study can produce robust estimates of $\mathrm{U}^{5} \mathrm{M}^{67}$ that are comparable to estimates directly calculated from complete birth history data that require detailed questionnaires. ${ }^{4768}$ The ease of summary birth history collection allows for its inclusion in national censuses and, in turn, analysis of U5M at finer spatial scales than is achievable through sample surveys. ${ }^{69}$ Our use of census data also enabled straightforward linkage of mortality outcomes with data on socioeconomic and living conditions at a common, local spatial scale and avoided issues of sample representativeness. Specifically, the data analysed were of all women aged 25-49 years in GAMA at the time of enumeration, and included those living in regular housing $(n=696279)$, homeless women/outdoor sleepers $(n=13950)$, women who were in schools, hospitals, army and service barracks and prisons $(\mathrm{n}=2361)$ and a small proportion from other locations $(n=991)$. People were not excluded from the census or this analysis based on migration status. Our analysis makes important methodological advancements from available neighbourhood-level U5M estimates in
GAMA. ${ }^{6165}$ First, we used a validated method for the use of summary birth history data in U5M estimation. ${ }^{46} 47$ Second, we applied established Bayesian methods widely used in small area estimation ${ }^{49}$ that allowed sharing of information across spatial units to make robust estimates for our study neighbourhoods.

Our results show a different spatial pattern of U5M across GAMA compared with previous estimates reported at the district level that indicated higher U5M in the largely periurban Ga West district and minimal variability across the rest of GAMA. ${ }^{31}$ This inconsistency could be due to a scarcity of data from areas outside the urban core used in the previous analysis. Their results rely heavily on data from the Demographic and Health Surveys that, for example, in 2008, sampled 41 women living in only four EAs in Ga West compared with 299 women living in 38 EAs in the AMA. Estimates for Ga West would, therefore, be informed by data with limited geographical coverage within the district and data from bordering rural areas, where child mortality is on average higher. ${ }^{6}$ By comparison, our study included data on children's births and deaths from 41270 women living in all 92 neighbourhoods of GA West.

Our study has several limitations to be considered for future studies. Changes in GAMA over the last decade may mean that our results do not reflect current patterns of U5M. Data from more recent sample surveys in GAMA, however, lack the coverage, scope and sample sizes of the census that enabled us to conduct our analysis at the neighbourhood level. The georeferenced data in the 2021 Ghana census, which is currently in progress, can be used to provide up-to-date estimates of U5M within GAMA and examine changes since 2010. As is the case for all studies of child mortality using census or sample survey data, we were limited to data on neighbourhood of residence at the time of the census and could not account for relocation since the death of a child. We also acknowledge that intervention efforts to prevent child mortality would benefit from more detailed information on the underlying causes of these deaths and age at which GAMA children are most vulnerable. ${ }^{70}{ }^{71}$ In our study, we were unable to separately estimate neonatal, infant or cause-specific mortality rates with the available methods for mortality estimation from summary birth history data and are unaware of any other data that are representative at the neighbourhood level and would enable this analysis. Investment in national civil registration systems across SSA, including in Ghana, could provide these data in real time and enable governments to monitor changes and progress in lowering child mortality and reducing inequalities. ${ }^{72}{ }^{73}$ Finally, we highlight that although we report U5M at a fine-spatial scale, populations within neighbourhoods may still be heterogeneous in their child mortality risk and its determinants, particularly within the more populous inner-city neighbourhoods. This is often discussed in the context of the Modifiable Areal Unit Problem, a statistical bias that can arise when area-level measurements are sensitive to the scale or zoning scheme used. ${ }^{74}$ 


\section{CONCLUSIONS}

Our city-scale results contribute to a small but growing number of studies showing that within-city variation in child mortality in SSA can be as large as the difference between urban and rural areas or between countries. ${ }^{61416}$ Global targets for child mortality, including SDG 3.2, and related monitoring efforts, focus entirely on national mortality rates. ${ }^{33}$ While important for benchmarking countries' overall performance, progress towards SDG 3.2 does not automatically benefit high mortality and vulnerable population subgroups within countries. ${ }^{31} 76$ The heterogeneity of U5M that we found across GAMA neighbourhoods motivates more localised and increasingly disaggregated information on child deaths in order to deliver effective interventions and continue progress toward meeting national and international targets in a region with relatively limited public health resources.

The determinants of child mortality are multifaceted, operate at multiple levels and can also interact with one another. As Ghana continues to urbanise, its cities and metropolitan areas, including GAMA, will play an increasingly important role in building on national child survival efforts. The heterogeneity in child mortality across Accra's neighbourhoods highlights the need for an explicit focus on equity in the context of rapid urbanisation in SSA, with an emphasis on the social determinants of health. Concentrated deprivation in households and neighbourhoods can compound the risk of child mortality. Our study identified neighbourhoods with high child mortality in GAMA's central and industrial areas, where the urban poor may still face financial and physical barriers to accessing health services, ${ }^{41} 77$ potentially compounding health risks associated with disadvantaged social and living conditions. Universal access to high-quality healthcare services can mitigate mortality inequalities in settings where children are born into different socioeconomic and environmental circumstances. $^{70} 7879$ There are proven, scalable healthcare interventions that reduce $\mathrm{U} 5 \mathrm{M}$, the causes of which are often preventable and/or treatable. ${ }^{70}$ In many lowand middle-income countries, the rise in facility births has not produced the expected improvements in child mortality, demonstrating the importance of continued access to quality care throughout the early years of life for all children and mothers across the socioeconomic spectrum. $^{7881}$

Child mortality in periurban neighbourhoods was on average lower than inner-city and industrial areas, but it was also more variable and inversely correlated with characteristics that indicate improved socioeconomic and living environments of neighbourhoods. Complementary investment in developing infrastructure and services in neighbourhoods outside of the urban core, while ensuring that conditions in densely populated central and industrial areas do not deteriorate, could further contribute to improving child mortality and promoting health equity.

\section{Author affiliations}

${ }^{1}$ Department of Epidemiology, Biostatistics and Occupational Health, McGill University, Montreal, Quebec, Canada

${ }^{2}$ Institute for Health and Social Policy, McGill University, Montreal, Quebec, Canada ${ }^{3}$ Department of Epidemiology and Biostatistics, School of Public Health, Imperial College London, London, UK

${ }^{4}$ MRC Centre for Environment and Health, Imperial College London, London, UK ${ }^{5}$ Regional Institute for Population Studies, University of Ghana, Accra, Ghana ${ }^{6}$ Department of Environmental Health Sciences, University of Massachusetts Amherst, Amherst, Massachusetts, USA

${ }^{7}$ Ghana Statistical Service, Accra, Ghana

${ }^{8}$ University of Cape Coast, Cape Coast, Ghana

${ }^{9}$ Department of Geography, McGill University, Montreal, Québec, Canada

${ }^{10}$ Department of Geography and Resource Development, University of Ghana, Legon, Greater Accra, Ghana

${ }^{11}$ Institute of Statistical, Social and Economic Research, University of Ghana, Accra, Ghana

${ }^{12}$ Abdul Latif Jameel Institute for Disease and Emergency Analytics, Imperial College London, London, UK

Acknowledgements We also thank Tzu-Wei Joy Tseng and Emmalin Buajitti for their help in preparation of the manuscript and helpful discussions during revisions.

Contributors $H B, M E, A A B, G O$ and JB developed the study concept. HB, AAB, SKA, JDA, SEM, REA, AC, GO and SAM contributed to data collation. HB conducted the statistical analysis with input from JEB, RA, AMS, BER, ME and JB. HB, AAB, REA, $S A M, B E R, M E$ and JB contributed to data interpretation. $H B$ wrote the first draft of the manuscript with input from JB. All authors contributed to revising and finalising the manuscript. $\mathrm{HB}$ and JB have primary responsibility for the final content. JB will act as guarantor.

Funding This work is supported by the Pathways to Equitable Healthy Cities grant from the Wellcome Trust [209376/Z/17/Z]. HB is supported by a Canadian Institute of Health Research Banting Postdoctoral Fellowship. For the purpose of Open Access, the author has applied a CC BY public copyright licence to any Author Accepted Manuscript version arising from this submission.

Disclaimer The funders had no role in the study design, data collection and analysis, decision to publish, or preparation of the manuscript.

Map disclaimer The inclusion of any map (including the depiction of any boundaries therein), or of any geographic or locational reference, does not imply the expression of any opinion whatsoever on the part of BMJ concerning the legal status of any country, territory, jurisdiction or area or of its authorities. Any such expression remains solely that of the relevant source and is not endorsed by BMJ. Maps are provided without any warranty of any kind, either express or implied.

Competing interests None declared.

Patient consent for publication Not applicable.

Provenance and peer review Not commissioned; externally peer reviewed.

Data availability statement Data are available in a public, open access repository. Data may be obtained from a third party and are not publicly available. Estimates of neighbourhood U5M will be made available at http://equitablehealthycities.org/ data-download/. The full microdata of the 2010 Ghana Population and Housing Census are with the Ghana Statistical Service and are not publicly available. Data from a random $10 \%$ sample of households enumerated in the 2010 Population and Housing census are publicly available and can be downloaded from Ghana Statistical Services online data catalogue (https://www2.statsghana.gov.gh/nada/ index.php/catalog/51).

Supplemental material This content has been supplied by the author(s). It has not been vetted by BMJ Publishing Group Limited (BMJ) and may not have been peer-reviewed. Any opinions or recommendations discussed are solely those of the author(s) and are not endorsed by BMJ. BMJ disclaims all liability and responsibility arising from any reliance placed on the content. Where the content includes any translated material, BMJ does not warrant the accuracy and reliability of the translations (including but not limited to local regulations, clinical guidelines, terminology, drug names and drug dosages), and is not responsible for any error and/or omissions arising from translation and adaptation or otherwise.

Open access This is an open access article distributed in accordance with the Creative Commons Attribution 4.0 Unported (CC BY 4.0) license, which permits others to copy, redistribute, remix, transform and build upon this work for any purpose, provided the original work is properly cited, a link to the licence is given, 
and indication of whether changes were made. See: https://creativecommons.org/ licenses/by/4.0/.

ORCID iD

Honor Bixby http://orcid.org/0000-0002-0513-5292

\section{REFERENCES}

1 United Nations Inter-agency Group for Child Mortality Estimation. Levels \& trends in child mortality. New York: UN, 2020.

2 GBD 2019 Demographics Collaborators. Global age-sexspecific fertility, mortality, healthy life expectancy (HALE), and population estimates in 204 countries and territories, 1950-2019: a comprehensive demographic analysis for the global burden of disease study 2019. Lancet 2020;396:1160-203.

3 GBD 2015 Child Mortality Collaborators. Global, regional, National, and selected subnational levels of stillbirths, neonatal, infant, and under-5 mortality, 1980-2015: a systematic analysis for the global burden of disease study 2015. Lancet 2016;388:1725-74.

4 Balk D, Pullum T, Storeygard A, et al. A spatial analysis of childhood mortality in West Africa. Popul Space Place 2004;10:175-216.

5 Corker J. Fertility and child mortality in urban West Africa: Leveraging geo-referenced data to move beyond the urban/rural dichotomy. Popul Space Place 2017;23:e2009.

6 Fink G, Günther I, Hill K. Slum residence and child health in developing countries. Demography 2014;51:1175-97.

7 United Nations Department of Economic and Social Affairs PD. World urbanization prospects, 2018 revision. New York: UN, 2019.

8 UN-Habitat. World cities report 2020, 2020.

9 Commission on Social Determinants of Health. Closing the gap in a generation: health equity through action on the social determinants of health: final report of the Commission on social determinants of health. World Health Organization, 2008.

10 Marmot M. Social determinants of health inequalities. Lancet 2005;365:1099-104.

11 Chao F, You D, Pedersen J, et al. National and regional under-5 mortality rate by economic status for low-income and middleincome countries: a systematic assessment. Lancet Glob Health 2018;6:e535-47.

12 Ezzati M, Webster CJ, Doyle YG, et al. Cities for global health. BMJ 2018;363:k3794.

13 Montgomery MR, Hewett PC. Urban poverty and health in developing countries: household and neighborhood effects. Demography 2005;42:397-425.

14 Günther I, Harttgen K. Deadly cities? spatial inequalities in mortality in sub-Saharan Africa. Popul Dev Rev 2012;38:469-86.

$15 \mathrm{Kyu} \mathrm{HH}$, Shannon HS, Georgiades K, et al. Association of urban slum residency with infant mortality and child stunting in low and middle income countries. Biomed Res Int 2013;2013:604974.

16 Timæus IM, Lush L. Intra-urban differentials in child health. Health Transit Rev 1995;5:163-90.

17 Agyei-Mensah S, Owusu G. Segregated by neighbourhoods? A portrait of ethnic diversity in the neighbourhoods of the Accra metropolitan area, Ghana. Popul Space Place 2010;16:499-516.

18 Musterd S. Handbook of urban segregation. Edward Elgar Publishing, 2020.

19 Elliott P, Wartenberg D. Spatial epidemiology: current approaches and future challenges. Environ Health Perspect 2004;112:998-1006.

20 Weeks JR, Hill AG, Getis A, et al. Ethnic residential patterns as predictors of intra-urban child mortality inequality in Accra, Ghana. Urban Geogr 2006;27:526-48.

21 Boing AF, Boing AC, Cordes J, et al. Quantifying and explaining variation in life expectancy at census tract, County, and state levels in the United States. Proc Natl Acad Sci U S A 2020;117:17688.

22 Dwyer-Lindgren L, Squires ER, Teeple S, et al. Small area estimation of under-5 mortality in Bangladesh, Cameroon, Chad, Mozambique, Uganda, and Zambia using spatially misaligned data. Popul Health Metr 2018;16:13.

23 Dwyer-Lindgren L, Stubbs RW, Bertozzi-Villa A, et al. Variation in life expectancy and mortality by cause among neighbourhoods in King County, WA, USA, 1990-2014: a census tract-level analysis for the global burden of disease study 2015. Lancet Public Health 2017;2:e400-10.

24 Rashid T, Bennett JE, Paciorek CJ, et al. Life expectancy and risk of death in 6791 communities in England from 2002 to 2019: highresolution spatiotemporal analysis of civil registration data. Lancet Public Health 2021;6:e805-16.

25 Monnat SM, Peters DJ, Berg MT, et al. Using census data to understand county-level differences in overall drug mortality and opioid-related mortality by opioid type. Am J Public Health 2019;109:1084-91.

26 Nakaya T, Honjo K, Hanibuchi T, et al. Associations of all-cause mortality with census-based neighbourhood deprivation and population density in Japan: a multilevel survival analysis. PLoS One 2014;9:e97802.

27 Diez Roux AV. Neighborhoods and health: what do we know? what should we do? Am J Public Health 2016;106:430-1.

28 Borrell LN, Diez Roux AV, Rose K, et al. Neighbourhood characteristics and mortality in the Atherosclerosis risk in Communities study. Int J Epidemiol 2004;33:398-407.

29 Parks MJ, Dodoo FN-A, Ayernor PK. Applying neighborhoodeffect research to a global south city: A case study of collective efficacy in Accra, Ghana's low-income areas. The Global South 2014;8:119-38.

30 Pearce N. The ecological fallacy strikes back. J Epidemiol Community Health 2000;54:326

31 Burstein R, Henry NJ, Collison ML, et al. Mapping 123 million neonatal, infant and child deaths between 2000 and 2017. Nature 2019;574:353-8.

32 Arku RE, Bennett JE, Castro MC, et al. Geographical inequalities and social and environmental risk factors for under-five mortality in Ghana in 2000 and 2010: Bayesian spatial analysis of census data. PLoS Med 2016;13:e1002038.

33 United Nations. Transforming our world: the 2030 agenda for sustainable development. New York: UN, 2015.

34 Bhutta ZA. Mapping the geography of child mortality: a key step in addressing disparities. Lancet Glob Health 2016;4:e877-8.

35 Ghana Statistical Service (GSS). Ghana population and housing census. Accra, Ghana: Ghana Statistical Service (GSS), 2010.

36 Owusa G. Decentralized development planning and fragmentation of metropolitan regions: the case of the greater Accra metropolitan area, Ghana. Ghana J Geogr 2015;7:1-24.

37 Yankson P, Bertrand M. Challenges of urbanization in Ghana. In: Ardayfio-Schandorf E, ed. The mobile city of Accra: urban families, housing and residential places, 2012: 25-46.

38 Akubia JEK, Bruns A. Unravelling the frontiers of urban growth: spatio-temporal dynamics of land-use change and urban expansion in greater Accra metropolitan area, Ghana. Land 2019;8:131.

39 Kayode GA, Grobbee DE, Koduah A, et al. Temporal trends in childhood mortality in Ghana: impacts and challenges of health policies and programs. Glob Health Action 2016;9:31907-07.

40 Ghana National health insurance act (act 650) 2003.

41 Blanchet NJ, Fink G, Osei-Akoto I. The effect of Ghana's National health insurance scheme on health care utilisation. Ghana Med J 2012;46:76-84.

42 Ministry of Health Ghana. Guidelines for implementing the exemption policy on maternal deliveries. Accra, Ghana: Ministry of Health, Ghana, 2004

43 Ministry of Health Ghana.. Under five's child health policy: 20072015. Accra, Ghana: Ministry of Health, Ghana, 2007.

44 Witter S, Garshong B, Ridde V. An exploratory study of the policy process and early implementation of the free NHIS coverage for pregnant women in Ghana. Int J Equity Health 2013;12:16.

45 Ghana Statistical Service (GSS), Ghana Health Service (GHS), ICF International. Ghana demographic and health survey 2014. Rockville, Maryland, USA: GSS, GHS, and ICF International, 2015.

46 Rajaratnam JK, Tran LN, Lopez AD, et al. Measuring underfive mortality: validation of new low-cost methods. PLoS Med 2010;7:e1000253.

47 Verhulst A. Child mortality estimation: an assessment of summary birth history methods using microsimulation. Demogr Res 2016;34:1075-128.

48 Hill K, You D, Inoue M, et al. Child mortality estimation: accelerated progress in reducing global child mortality, 1990-2010. PLoS Med 2012;9:e1001303.

49 Besag J, York J, Mollié A. Bayesian image restoration, with two applications in spatial statistics. Ann Inst Stat Math 1991;43:1-20.

50 Deaton A. The analysis of household surveys: a microeconometric approach to development policy. Baltimore, MD: Published for the World Bank [by] Johns Hopkins University Press, 1997.

51 Deaton A, Zaidi S. Guidelines for constructing consumption aggregates for welfare analysis. LSMS working paper No. 135. Washington, D.C.: World Bank, 2002.

52 Cavanaugh A, Bixby $\mathrm{H}$, Schmidt AM. Locating poverty and inequality: an application of small area estimation methods using survey and census data from Ghana. Manuscript in preparation 2021.

53 Owusu G. Social effects of poor sanitation and waste management on poor urban communities: a neighborhood-specific study of Sabon Zongo, Accra. J Urban 2010;3:145-60. 
54 Guiteras R, Levinsohn J, Mobarak AM. Sanitation subsidies. encouraging sanitation investment in the developing world: a clusterrandomized trial. Science 2015;348:903-6.

55 Zhou Z, Dionisio KL, Verissimo TG, et al. Chemical composition and sources of particle pollution in affluent and poor neighborhoods of Accra, Ghana. Environ Res Lett 2013;8:044025.

56 Jorgenson AK, Rice J. Urban slum growth and human health: a panel study of infant and child mortality in less-developed countries, 1990-2005. J Poverty 2010;14:382-402.

57 Rice J, Rice JS. The concentration of disadvantage and the rise of an urban penalty: urban slum prevalence and the social production of health inequalities in the developing countries. Int $J$ Health Serv 2009;39:749-70.

58 Ezeh A, Oyebode O, Satterthwaite D, et al. The history, geography, and sociology of slums and the health problems of people who live in slums. Lancet 2017;389:547-58.

59 Kimani-Murage EW, Fotso JC, Egondi T, et al. Trends in childhood mortality in Kenya: the urban advantage has seemingly been wiped out. Health Place 2014;29:95-103.

60 Jankowska MM, Weeks JR, Engstrom R. Do the most vulnerable people live in the worst slums? A spatial analysis of Accra, Ghana. Ann GIS 2011:17:221-35.

61 Jankowska MM, Benza M, Weeks JR. Estimating spatial inequalities of urban child mortality. Demogr Res 2013;28:33-62.

62 Hewett PC, Montgomery MR. Poverty and public services in developing-country cities. policy research division working paper No. 154. New York: Population Council, 2001.

63 Temin M, Montgomery M, Engebretsen S. Girls on the move: adolescent girls \& migration in the developing world. New York: Population Council, 2013

64 UNICEF, Institute of Statistical Social and Economic Research (ISSER) University of Ghana, Carolina Population Center University of North Carolina at Chapel Hill. Ghana leap 1000 programme: Endline evaluation report. Ghana: Ministry of Gender, Children and Social Protection, 2018

65 Toure S, Weeks J, Lopez-Carr D, et al. Evaluating links between dynamic urban landscapes and under-five child mortality in Accra, Ghana. Demogr Res 2020;42:589-614.

66 Grant R, Yankson P. Accra. Cities 2003;20:65-74.

67 Hill K, Lopez AD, Shibuya K, et al. Interim measures for meeting needs for health sector data: births, deaths, and causes of death. Lancet 2007;370:1726-35.
68 Silva R. Child mortality estimation: consistency of under-five mortality rate estimates using full birth histories and summary birth histories. PLoS Med 2012;9:e1001296.

$69 \mathrm{Li}$ Z, Hsiao Y, Godwin J, et al. Changes in the spatial distribution of the under-five mortality rate: Small-area analysis of $122 \mathrm{DHS}$ surveys in 262 subregions of 35 countries in Africa. PLoS One 2019;14:e0210645.

70 Bhutta ZA, Das JK, Bahl R, et al. Can available interventions end preventable deaths in mothers, newborn babies, and stillbirths, and at what cost? Lancet 2014;384:347-70.

71 Keats EC, Das JK, Salam RA, et al. Effective interventions to address maternal and child malnutrition: an update of the evidence. Lancet Child Adolesc Health 2021;5:367-84.

72 Eilerts H, Romero Prieto J, Eaton JW, et al. Age patterns of under-5 mortality in sub-Saharan Africa during 1990-2018: a comparison of estimates from demographic surveillance with full birth histories and the historic record. Demogr Res 2021;44:415-42.

73 Lopez AD, McLaughlin D, Richards N. Reducing ignorance about who dies of what: research and innovation to strengthen CRVS systems. BMC Med 2020;18:58.

74 Kwan M-P. The limits of the neighborhood effect: contextual uncertainties in geographic, environmental health, and social science research. Ann Am Assoc Geogr 2018;108:1482-90.

75 United Nations. The millennium development goals report 2015. New York: UN, 2015.

76 Burke M, Heft-Neal S, Bendavid E. Sources of variation in under-5 mortality across sub-Saharan Africa: a spatial analysis. Lancet Glob Health 2016;4:e936-45.

77 Earth Institute Millennium Cities Initiative. AMA community upgrading profile: Nima-Maamobi drain area. New York: The Earth Institute at Columbia University, 2012

78 Roder-DeWan S, Nimako K, Twum-Danso NAY, et al. Health system redesign for maternal and newborn survival: rethinking care models to close the global equity gap. BMJ Glob Health 2020;5:e002539.

79 Kruk ME, Gage AD, Joseph NT, et al. Mortality due to lowquality health systems in the universal health coverage era: a systematic analysis of amenable deaths in 137 countries. Lancet 2018;392:2203-12

80 Bhutta ZA, Das JK, Walker N, et al. Interventions to address deaths from childhood pneumonia and diarrhoea equitably: what works and at what cost? Lancet 2013;381:1417-29.

81 Campbell OMR, Calvert C, Testa A, et al. The scale, scope, coverage, and capability of childbirth care. Lancet 2016;388:2193-208. 